\title{
Lecithin: Cholesterol Acyltransferase Activity and Fatty Acid Composition of Erythrocyte Phospholipids in Friedreich's Ataxia
}

\author{
Y.S. HUANG, Y.L. MARCEL, C. VEZINA, A. BARBEAU and J. DAVIGNON
}

SUMMARY: In a study of the fatty acid composition of erythrocyte membrane phospholipids in Friedreich's ataxia, a lower percentage of linoleic acid in phosphatidylcholine was demonstrated. An enzyme involving the exchange of lipids between plasma and erythrocyle membrane, lecithin: cholesteryl acyltransferase (LCAT) was also studied. It was found that the LCA T activity had a trend towards low values. However, crossing-over studies indicated that when the LCAT enzyme of patients was exposed to its own substrate it gave low activity values but that the result reverted to normal when control substrate was used.

RESUME: Nous avons étudié la composition en acides gras des phospholipides de la membrane erythrocytaire dans l'ataxie de Friedreich et avons trouvé un pourcentage plus bas d'acide linoléique dans la phosphatidylcholine. Nous avons aussi étudié la lecithin: cholesteryl acetyl transferase (LCAT), un enzyme impliqué dans l'échange des lipides entre le plasma et les membranes. L'activité du LCAT avait tendance à être basse. Cependant des études de dosage croisé ont montré que lorsque le LCAT des patients était exposéà leurs propres substrats, les valeurs étaient basses, alors que les résultats retournaient à la normale lorsqu'un substrat normal était présenté à l'enzyme.

\footnotetext{
From The Department of Lipid Metabolism and Atherosclerosis Research, the Laboratory of Lipid Research and the Department of Neurobiology, Clinical Research Institute of Montreal.

Reprint requests for the entire supplement on Friedreich's Ataxia (Phase III) to: Dr. André Barbeau, Clinical Research Institute of Montreal, 110 Pine Avenue West, Montreal, Quebec H2W IR7.
}

\section{INTRODUCTION}

We have previously shown that plasma high density lipoproteins (HDL) in Friedreich's ataxia patients contained a smaller amount of protein, hence a higher proportion of cholesterol, than HDL from healthy control subjects (Huang et al, 1978). This abnormal ratio was tentatively ascribed to an abnormal composition of the lipid moiety. Further studies (Davignon et al, 1979) disclosed a relative deficiency in the linoleic acid (18:2) content of cholesteryl esters (CE) in both total plasma and HDL with a compensatory increase in saturated and monounsaturated fatty acids. HDL phospholipids (PL) were also deficient in 18:2 but total plasma PL and triglyceride (TG) fatty acid profiles were unaffected. Feeding large amounts of soya lecithin rich in 18:2 failed to increase significantly the 18:2 content of HDL-CE and HDL-PL but lowered the palmitoleic and oleic acid content of all 3 lipid classes and tended to increase the 18:2 content of plasma TG. These results suggested a partial defect in the incorporation of $18: 2$ into chylomicron phospholipids within the intestinal mucosa. It was postulated that if this was the case, the 18:2-deficient phospholipids of HDL derived from chylomicrons would be transferred to cell membranes such as that of the red blood cell and serve as substrate for lecithin:cholesterol acyltransferase (LCAT), which would in turn produce the 18:2-deficient cholesteryl esters found in HDL and other lipoproteins. The purpose of the work reported here was to verify this hypothesis by measuring the fatty acid profile of red blood cell phospholipids and determine whether LCAT activity was reduced in Friedreich's ataxia, since an 18:2 deficient lecithin (phosphatidyl-choline,
PC) would constitute a poor substrate for this enzyme.

\section{MATERIAL AND METHOD} Subjects and sampling:

These studies were carried out in 14 patients affected with Friedreich's ataxia defined according to the criteria of the Quebec Cooperative Study of Friedreich's Ataxia (Barbeau, 1976) and in 11 healthy volunteers of comparable age. There were an equal number of males and females in the Friedreich's group with a mean age $( \pm$ SD) of $25.0 \pm 5.5$ years (range 17 to 34). There were 6 males and 5 females among the control subjects. Their average age was $25.6 \pm 4.5$ (range 19 to 33). None of the 25 subjects was obese. Among the Friedreich's patients only one had overt diabetes, and 3 had fasting hyperbilirubinemia. None were bedridden but 8 were confined to wheelchairs. Blood samples were collected in the morning, after a 12 hour fast, in tubes containing EDTA ( $1 \mathrm{mg} / \mathrm{ml}$ ), kept on crushed ice until centrifuged $(1200 \times \mathrm{g})$ at $4^{\circ} \mathrm{C}$ to separate plasma and red blood cell before processing.

\section{Analysis of red blood cell lipids:}

Separated red blood cells were washed 3 times with an equal volume of $0.5 \mathrm{~m} \mathrm{NaCl}$ containing $1 \mathrm{mM}$ EDTA. They were resuspended in the same solution to an hematocrit value of $50 \%$. Total lipids were extracted from $6 \mathrm{ml}$ aliquots of this suspension according to the method of Folch et al (1957) modified by Dodge and Phillips (1967). Similarly the method of Folch et al (1957) was used to extract total lipids from aliquots of plasma.

Aliquots of the total lipid extracts (red blood cells) were used to separate the major phospholipid classes by thin 
layer chromatography on silica gel $\mathrm{H}$ coated plates $(0.5 \mathrm{~mm}$ thickness, $20 \mathrm{x}$ $20 \mathrm{~cm}$ ). The plates were developed in a chloroform/methanol/glacial acetic acid/water mixture (25:15:4:2, v/v) (Skipski et al, 1963) containing 50 $\mathrm{mg} / 100 \mathrm{ml}$ antioxidant butylated hydroxy toluene (BHT). The phospholipid bands were visualized under ultraviolet light $(254 \mathrm{~nm})$ after spraying the plates with a $0.025 \%$ solution of 2,7-dichlorofluorescein in propanol. The bands corresponding to standards of phosphatidylcholine (PC), phosphatidyl ethanolamine (PE) and phosphatidyl serine (PS) were scraped into test tubes and hydrolyzed and methylated according to the method of Morrison and Smith (1964). The fatty acid methyl esters of each of these phospholipid classes were identified and quantitated by gas liquid chromatography using a Hewlett Packard F \& $M$ model 402 apparatus equipped with an hydrogen flame ionization detector and an automatic integrator (HP model 3371B). The samples were run on a 6-foot glass column of $10 \%$ Silar 10C coated on Gas Chrom Q (100-120 mesh, Applied Science Laboratories) at $185^{\circ} \mathrm{C}$ as previously described (Davignon et al, 1979).

\section{LCAT assay:}

The activity of lecithin:cholesterol acyltransferase was measured by the method of Stokke and Norum (1970). The test sample was added to the incubation mixture which contained $50 \mu \mathrm{l}$ of a cholesterol-albumin emulsion

TABLE 1

Fatty Acid Composition Of Erythrocyte Phosphatidyl Ethanolamine And Phosphatidyl Serine In Controls And Patients With Friedreich's Ataxia

\begin{tabular}{crrrr}
\hline & \multicolumn{2}{c}{ PE } & \multicolumn{2}{c}{ PS } \\
Fatty acid & \multicolumn{1}{c}{$\begin{array}{c}\text { Control } \\
(\mathbf{n}=11)\end{array}$} & \multicolumn{1}{c}{$\begin{array}{c}\text { Ataxia } \\
(\mathbf{n}=14)\end{array}$} & \multicolumn{1}{c}{$\begin{array}{c}\text { Control } \\
(\mathbf{n}=11)\end{array}$} & \multicolumn{1}{c}{$\begin{array}{c}\text { Ataxia } \\
(\mathbf{n}=14)\end{array}$} \\
\hline $16: 0$ & $15.88 \pm 2.19$ & $15.67 \pm 2.22$ & $4.57 \pm 1.66$ & $4.87 \pm 2.13$ \\
$16: 1$ & $0.63 \pm 0.42$ & $0.82 \pm 0.47$ & $0.44 \pm 0.61$ & $0.95 \pm 1.10$ \\
$18: 0$ & $15.44 \pm 2.00$ & $14.61 \pm 1.50$ & $41.19 \pm 3.21$ & $42.31 \pm 2.95$ \\
$18: 1$ & $19.74 \pm 1.76$ & $19.74 \pm 2.46$ & $9.34 \pm 2.45$ & $9.64 \pm 2.78$ \\
$18: 2$ & $4.74 \pm 1.17$ & $3.94 \pm 0.69$ & $2.17 \pm 0.58$ & $1.74 \pm 0.79$ \\
$20: 4$ & $23.02 \pm 1.62$ & $22.75 \pm 2.48$ & $24.83 \pm 2.80$ & $25.13 \pm 3.40$ \\
$22: 4$ & $6.56 \pm 1.52$ & $6.84 \pm 0.74$ & $2.06 \pm 0.78$ & $2.07 \pm 0.81$ \\
$22: 5$ & $3.52 \pm 0.90$ & $4.03 \pm 1.40$ & $2.04 \pm 0.82$ & $1.89 \pm 0.87$ \\
$22: 6$ & $4.26 \pm 1.47$ & $4.65 \pm 1.97$ & $5.00 \pm 2.05$ & $3.26 \pm 2.13$ \\
\hline
\end{tabular}

with a $0.3 \mu \mathrm{Ci}$ of $4-{ }^{14} \mathrm{C}$-cholesterol and $25 \mu$ l of 5,5-dithio-bis-(2-nitrobenzoic acid) (DTNB, final concentration 1.4 $\mathrm{mM}$ ). After a four-hour preincubation period at $37^{\circ} \mathrm{C}$ to allow equilibration of the ${ }^{14} \mathrm{C}$-cholesterol with the substrate lipoprotein cholesterol in the presence of this inhibitor of the reaction (DTNB), LCAT activity was initiated with $25 \mu \mathrm{l}$ of $\beta$-mercaptoethanol (final concentration $15 \mathrm{mM}$ ). The reaction was stopped after $30 \mathrm{~min}$. by the addition of a methanol/chloroform mixture $(5 \mathrm{ml}$ and $7.5 \mathrm{ml}$ respectively which separate) into two phases after the addition of $2.5 \mathrm{ml}$ of a $0.75 \% \mathrm{NaCl}$ solution. The bottom phase containing the lipids was dried under nitrogen redissolved in $50 \mu \mathrm{l}$ of chloroform and applied on a thin layer chromatographic plate for the separation and measurements of free and esterified cholesterol radioactivity according to Marcel et al (1971). LCAT activity was expressed as nmoles of cholesterol esterified per hour per ml of plasma.

The LCAT assay was carried out in two separate experiments. The first one consisted in a standard LCAT activity measurement on a $250 \mu \mathrm{l}$ aliquot of fresh plasma from Friedreich patients $(n=12)$ and control subjects $(\mathrm{n}=10)$. The second experiment consisted in separating the substrate $(\mathrm{S}, \mathrm{d}<1.21 \mathrm{~g} / \mathrm{ml}$ ultracentrifugal fraction) from the enzyme (E,d $>1.21$
TABLE 2

Fatty Acid Composition Of Erythrocyte Phosphatidyl Choline In Controls And Patients With Friedreich's Ataxia

\begin{tabular}{ccc}
\hline Fatty acid & $\begin{array}{c}\text { Control } \\
(\mathbf{n}=11)\end{array}$ & $\begin{array}{c}\text { Ataxia } \\
(\mathbf{n}=14)\end{array}$ \\
\hline $16: 0$ & $33.31 \pm 1.48$ & $34.28 \pm 2.28$ \\
$16: 1$ & $1.07 \pm 0.36$ & $1.30 \pm 0.42$ \\
$18: 0$ & $11.71 \pm 1.00$ & $11.47 \pm 1.79$ \\
$18: 1$ & $18.76 \pm 1.48$ & $19.90 \pm 2.29$ \\
$18: 2$ & $21.51 \pm 1.71$ & $18.96 \pm 1.82^{*}$ \\
$20: 4$ & $6.14 \pm 1.50$ & $6.15 \pm 1.25$ \\
$22: 6$ & $1.01 \pm 0.70$ & $0.93 \pm 0.67$ \\
\hline
\end{tabular}

TABLE 3

LCAT Activity In Recombined Enzyme And Substrate Fractions Separated From Control $(n=1)$ And Friedreich's Ataxia $(n=6)$

\begin{tabular}{lcc}
\hline & $\begin{array}{c}\text { LCAT activity (nmoles CE/hr/ml plasma) } \\
\text { control substrate } \\
\text { (SC) }\end{array}$ & $\begin{array}{c}\text { ataxia substrate } \\
\text { (SA) }\end{array}$ \\
\hline $\begin{array}{l}\text { control enzyme } \\
\text { (EC) }\end{array}$ & 95.2 & $84.7 \pm 17.7$ \\
$\begin{array}{l}\text { ataxia enzyme } \\
\text { (EA) }\end{array}$ & $92.0 \pm 14.5$ & $69.3 \pm 18.2^{*}$ \\
\hline
\end{tabular}

*significantly different from EA + SC (p<0.05) but not from SA + EC 


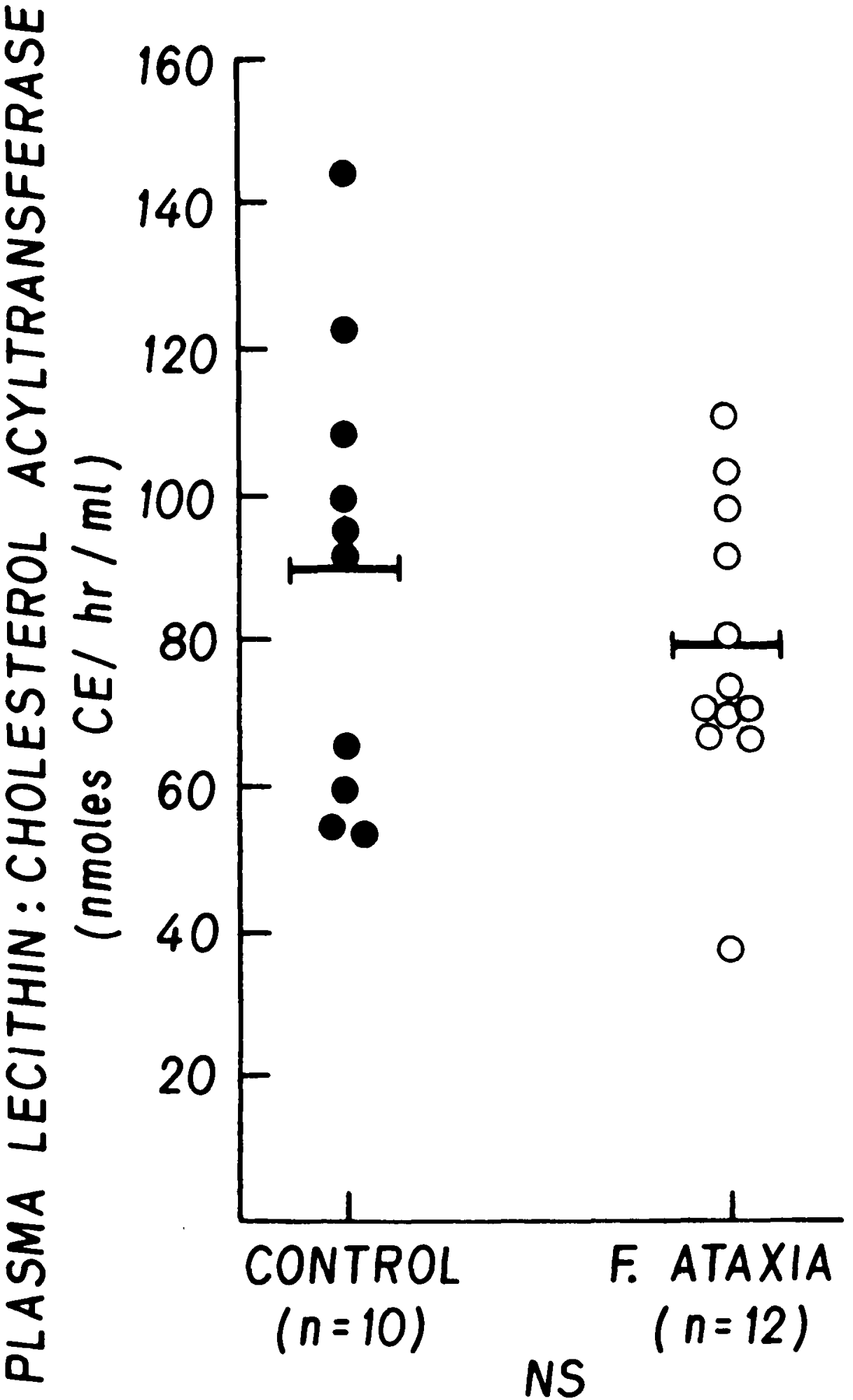

Figure 1 - Plasma lecithin:cholesterol acyltransferase activity in normal $(\bullet)$ and in patients with Friedreich's ataxia (o). The solid line is the mean.

$\mathrm{g} / \mathrm{ml}$ fraction) in one control (C) subject and 6 cases of Friedreich's ataxia (A). The LCAT assay was then carried out in a cross over design with various recombinations in order to distinguish between a substrate effect or a defect in enzyme activity. Thus the LCAT activity of the control subject was tested against its own substrate $(\mathrm{EC}+\mathrm{SA})$ : Conversely the LCAT activity of the 6 patients was tested against their own substrate (EA + SA) and against the substrate of the normal subject $(E A+S C)$. The two fractions were obtained from $12.5 \mathrm{ml}$ aliquots of plasma by preparative ultracentrifugation according to Havel et al (1955) adjusting the density at $1.21 \mathrm{~g} / \mathrm{ml}$ with solid $\mathrm{KBr}$ and spinning $40 \mathrm{~h}$ at $4^{\circ} \mathrm{C}$ at $110,000 \times \mathrm{g}$. Both the $\mathrm{d}<1.21 \mathrm{~g} / \mathrm{ml}$ fraction containing all the major plasma lipoprotein fractions and serving as substrate in this experiment and the $\mathrm{d}>1.21 \mathrm{~g} / \mathrm{ml}$ fraction containing LCAT and the other plasma proteins were dialyzed overnight against 0.15 $\mathrm{M} \mathrm{NaCl}$ containing $1 \mathrm{mM} \mathrm{Na}_{2}$ EDTA (100 volumes changed twice) at $4^{\circ} \mathrm{C}$. The first fraction (S) was adjusted to a volume of $3.5 \mathrm{ml}$ and the second (E) to $9.0 \mathrm{ml}$ with saline. Aliquots equivalent to $250 \mu \mathrm{l}$ of the original volume of plasma were used for the assay (i.e. 70 $\mu \mathrm{l}$ of $\mathrm{S}$ and $180 \mu \mathrm{l}$ of E). Aliquots of LP-fraction were extracted for measurement of unesterified cholesterol by gas liquid chromatography according to Marcel and Vézina (1973).

\section{RESULTS}

The fatty acid profile of erythrocyte phosphatidyl ethanolamine and phosphatidyl serine was the same in Friedreich's ataxia and in normal subjects (table 1), but the fatty acid composition of erythrocyte phosphatidyl choline differed. The percentage of linoleic acid in PC was significantly lower $(\mathrm{p}<0.01)$ in the patients than in the controls (table 2) although some individual values overlapped.

The mean plasma LCAT activity tended to be lower in Friedreich's ataxia $(89.0 \pm 31.0 \mathrm{nmoles} \mathrm{CE} / \mathrm{h} / \mathrm{ml}$ versus $78.0 \pm 20.0$ in the controls), but the difference was not statistically significant (figure 1).

In the recombination experiment LCAT enzyme activity was the same in the control subject and in the cases of Friedreich's ataxia when it was tested against a normal substrate (table 3 ). Indeed, the LCAT activity of the patients was in the normal range and virtually the same as that of the control subject used for comparison. In contrast the substrate from Friedreich patients yielded less cholesteryl esters when tested against both sources of 


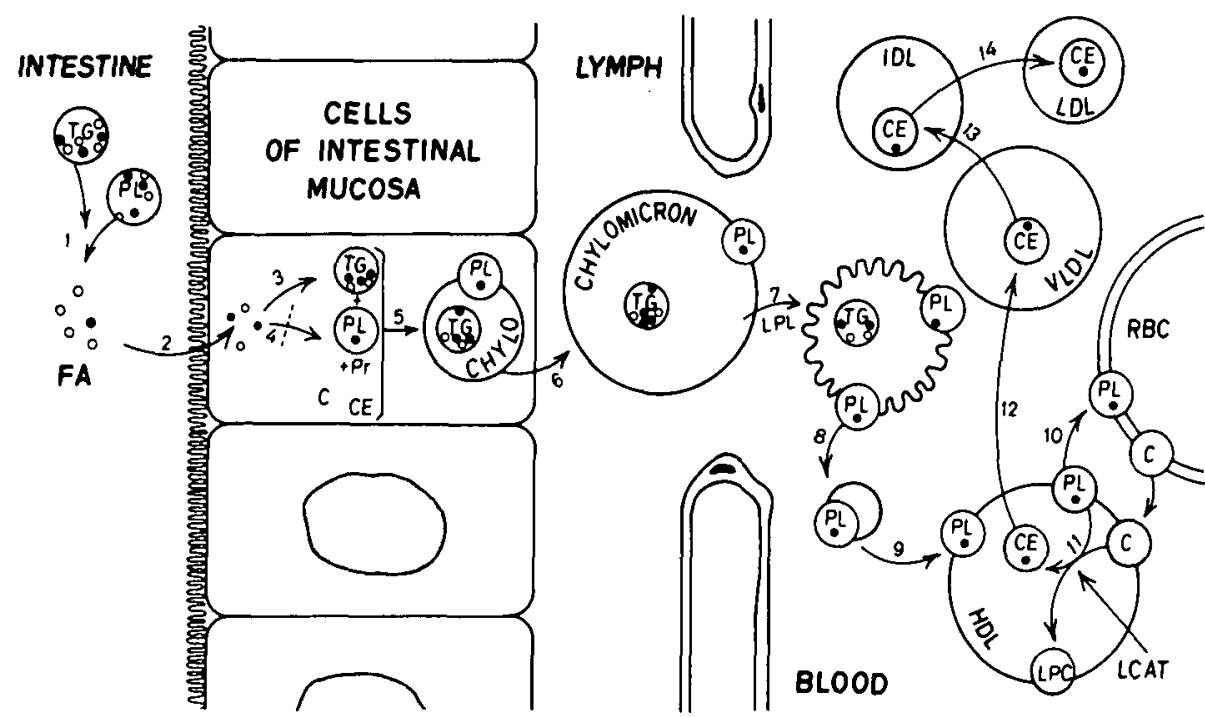

Figure 2 - Working hypothesis and tentative explanation for the relative and selective deficiency in linoleic acid in Friedreich's Ataxia. Dietary triglycerides (TG) and phospholipids (PL) are hydrolyzed in the intestine (1) to release fatty acids including linoleic acid (18:2) represented by black dots. These fatty acids are absorbed (2), incorporated normally into triglycerides (3) but not sufficiently into the phospholipids (4) of the Friedreich patient. The association of TG, PL, cholesterol (C) and cholesteryl esters (CE) to apolipoproteins synthesized in the intestinal mucosa result in the formation of chylomicrons (5) which are relatively deficient in 18:2. These fat globules are transferred into the lymph (6) to reach the blood. Lipoprotein lipase gradually reduce their TG content (7) and their surface rich in protein, phospholipids and cholesterol becomes in excess relative to the volume of the particle redundant and irregular. Pieces of this la mellar structure detach (8) to form vesicles which are taken up by HDL (9) (Tall and Small, 1978). Thus the chylomicron surface transfers to HDL phospholipids that are deficient in 18:2. These PL will be incorporated as such in the red blood cell membrane (10) and serve as substrate for lecithin cholesterol acyltransferase (LCAT) (I1) to form cholesteryl esters the composition of which will be relatively deficient in 18:2. These CE are then transferred to VLDL (12) who will follow their catabolic cascade to intermediate density lipoproteins (IDL) (13) and finally to LDL (14). The CE of the LDL will thus be also deficient in 18:2. This scheme reconciles the findings of Davignon et al (1979) which showed a deficiency in the 18:2 content of the CE of all lipoprotein fractions and of HDL phospholipids, a deficit which may not be corrected by the oral administration of soya lecithin rich in 18:2. It is also in agreement with a lowered level of 18:2 in red blood cell lecithin and a lowered LCAT activity related to a substrate effect reported in this paper.

enzyme. Thus the low LCAT activity observed in 6 patients when their enzyme was tested against their own substrate was completely reversed to normal when the same enzyme samples were exposed to a normal substrate $(p<0.05)$.

\section{DISCUSSION}

The finding of a lower percentage of linoleic acid (18:2) in the red blood cell PC of Friedreich's ataxia patients is consistant with the hypothesis that the membrane of the erythrocyte has exchanged with circulating HDL, phospholipid molecules which were deficient in 18:2.

It has been shown that nearly $60 \%$ of membrane phospholipids are exchangeable (Reed, 1968) mainly with HDL phospholipids. The fact that erythrocyte PE and PS did not seem to share this effect might indicate that they are derived from a different source. Indeed these membrane phospholipids have been reported to show virtually no exchange capability with plasma lipoproteins (Reed, 1968; Nelson, 1972). In addition they are present in very small amount (3.6 and 1.9\% of total phospholipids respectively) in plasma (Phillips and Dodge, 1967).

The LCAT reaction has been given an important role in the removal of free cholesterol from cellular membranes (Glomset, 1968 and 1970). In this process LCAT removes a polyun- saturated fatty acid (mostly linoleic acid) from the 2-position of PC, mainly located in the HDL fraction, to yield lysolecithin (LPC) and cholesteryl esters which are enriched in linoleic acid. These in turn are transferred by a more or less elaborate system (Nichols and Smith, 1965; Sniderman et al, 1978 ) to very low density lipoproteins (VLDL). We surmised that HDL phospholipids deficient in 18:2 as reported in Friedreich's ataxia would constitute a poor substrate for the LCAT enzyme and postulated a reduced LCAT activity in this disease (Davignon et al, 1979). Although the mean activity was lower in the Friedreich patients as compared to control, the difference did not reach statistical significance. Similar results had been obtained by Yao et al (1976) in a smaller group of patients. Our recombination studies however constituted a much more sensitive test to detect a substrate effect. They clearly demonstrated that the LCAT enzyme itself was not defective in Friedreich's ataxia since the low activity found in 6 patients was completely reversed to normal when the enzyme in each of the 6 cases was allowed to react with the normal substrate of a control subject. This is an added element in support of our working hypothesis (Davignon et al, 1979) which is summarized in figure 2. Recently evidence has been obtained which indicates that the PC used in the LCAT reaction might be regenerated from lysolecithin through another enzyme closely linked to LCAT, lysolecithin acyltransferase (LLAT) which is activated by LDL (Subbaiah and Bagdade, 1978 and 1979). It would be of interest to examine its activity in Friedreich's ataxia.

It is possible that Friedreich's ataxia and other related diseases might represent a partial or selective essential fatty acid deficiency. Huang et al (1980) have recently shown that some of the symptoms and biochemical abnormalities of deficiency may be attributed to a relative deficiency in essential fatty acids (EFA), in the absence of an increase in the triene/ tetraene ratio (mainly 20:3 $\omega 9 / 20: 4 \omega 6$ fatty acids), a ratio which has heretofore been regarded as the major criteria for EFA deficiency. These authors have shown that zinc depriva- 
tion induces in rats a relative metabolic unavailability in linoleic acid, probably through an inhibition of the $\Delta 6$ desaturase enzyme. The animals develop clinical signs of EFA deficiency, a relative hypertrophy of heart, lung, kidney, testis and adrenals, an atrophy of spleen, thymus and adipose tissue as well as a lowering of plasma cholesterol and triglycerides in the absence of any change in the triene/tetraene ratio. These manifestations, including the stunted growth, are reversed by the administration of gamma-linoleic acid $(18: 3 \omega 6)$ which is an EFA that bypasses the $\Delta 6$ desaturase step. It is possible that the multisystem disease characterizing Friedreich's ataxia might be related to another form of relative EFA deficiency. The function of some membranes, such as that of the heart mitochondria, might be very sensitive to a small change in fatty acid composition. A relative deficiency in 18:2 at this site could account for the myocardial disease and possibly for the progressive muscle weakness seen in Friedreich's ataxia (See Barbeau, this issue). These new avenues of research should be explored in depth.

Although our findings of a lowered 18:2 content in plasma cholesteryl esters and PC in Friedreich's ataxia (Davignon et al, 1979) did confirm and extend those of Yao et al (1976) and of Yao and Dyck (1978), a recent study by Walker et al (1980) did not yield similar results. The discrepancy might be accounted for by a difference in the selection of the control group (disabled individuals versus normal age and sex matched volunteers) and by a difference in the genetic make-up of the Friedreich cases. Their patients were much older on the average and had no hyperbilirubinemia; it is possible that they might represent a more heterogenous group than the one we have examined. A difference in methodology could also account for their inability to detect an abnormal protein/lipid ratio in HDL. In our initial study of plasma HDL (Huang et al, 1978) the protein and phospholipid values were obtained by differential ultracentrifugation, whereas the cholesterol and triglycerides were measured by a combination of ultracentrifugation and dextran sulfate $(2,000,000$ daltons) precipitation. The Hatch and Lees method
(1968) used for the latter tends to underestimate the $\mathrm{HDL}_{2}$ fraction (Wolf, Huang and Davignon, unpublished observation). We have repeated the measurements using a selective precipitation method (Burstein et al, 1970) with dextran sulfate of 15,000 daltons. We did not observe an excess of triglycerides in the HDL of Friedreich this time, but could confirm the same reduction in the protein/ cholesterol ratio (Wolf, Huang and Davignon, unpublished observation) observed in the initial study.

\section{ACKNOWLEDGEMENTS}

This study was supported by the "Association Canadienne de l'Ataxie de Friedreich" and the Medical Research Council of Canada.

The authors wish to thank Miss Danielle Bedard, R.N. and Mrs. Denise Brossard for their help with the patients. They are grateful to Mr. Michel Tremblay, Miss Lucie Boulet and Miss Murielle Paquette for their technical assistance and to Mrs. Réjeanne Ouellet and Mrs. Andrée Giroux for the preparation of the manuscript.

\section{REFERENCES}

BARBEAU, A. (1976). Friedreich's Ataxia 1976 - An overview. Can. J. Neurol. Sci. 3: 389397.

BURSTEIN, M., SCHOLNICK, H.R. and MORFIN, R. (1970). Rapid method for the isolation of lipoproteins from human serum by precipitation with polyanions. J. Lipid Res. 11: 583-595.

DAVIGNON, J., HUANG, Y.S., WOLF, J.P. and BARBEAU, A. (1979). Fatty acid profile of major lipid classes in plasma lipoproteins of patients with Friedreich's Ataxia - demonstration of a low linoleic acid content most evident in the cholesterolester fraction. Can. J. Neurol. Sci. 6: 275283.

DODGE, J.T. and PHILLIPS, G.B. (1967). Composition of phospholipids and of phospholipid fatty acids and aldehydes in human red cells. J. Lipid Res. 8: 667-675.

FOLCH, J., LEES, $M$. and SLOANESTANLEY, G.H. (1957). A simple method for the isolation and purification of total lipids from animal tissue. J. Biol. Chem. 226: 497-509.

GLOMSET, J.A. (1968). The plasma lecithin: cholesterol acyltransferase reaction. J. Lipid Res. 9: 155-167.

GLOMSET, J.A. (1970). Physiological role of lecithin-cholesterol acyltransferase. Am. J. Clin. Nutr. 23: 1129-1136.

HATCH, F.T. and LEES, R.S. (1968). Practical methods for plasma lipoprotein analysis. Adv. Lipid Res. 6: 1-68.

HAVEL, R.J., EDER, H.A. and BRAGDON, J.H. (1955). The distribution and chemical composition of ultracentrifugally separated lipoproteins in human serum. J. Clin. Invest. 34: 1345-1353.
HUANG, Y.S., CUNNANE, S.C., HORROBIN. D.F. and DAVIGNON, J. (1980). Most biological effects of zinc deficiency corrected by $\gamma$-linolenic acid $(18: 3 \omega 6)$ but not by linoleic acid (18:2 $\omega$ 6). Submitted for publication.

HUANG, Y.S., NESTRUCK, A.C., BARBEAU, A., BOUCHARD, J.P. and DAVIGNON, J. (1978). Plasma lipids and lipoprotein in Friedreich's ataxia and familial spastic ataxia - evidence for an abnormal composition of high density lipoproteins. Can. J. Neurol. Sci. 5: 149-156.

MARCEL, Y.L., FABIEN, H.D, and DAVIGNON, J. (1971). Net esterification in vitro of plasma cholesterol in human primary hyperlipidemia. Lipids 6: 722-726.

MARCEL, Y.L. and VEZINA, C. (1973). A method for the determination of the initial rate of reaction of lecithin:cholesterol acyltransferase in human plasma. Biochim. Biophys. Acta 306: 497-504.

MORRISON, W.R. and SMITH, L.M. (1964). Preparation of fatty acid methyl esters and dimethylacetals from lipids in the boron fluoride-methanol. J. Lipid Res. 5: 600-608.

NELSON, G.J. (1972). Lipid composition and metabolism of erythrocytes. In: Blood lipids and lipoprotein: quantitation, composition and metabolism. G.J. Nelson (ed). Wiley, Interscience, New York, pp. 317-385.

NICHOLS, A.V. and SMITH, L. (1965). Effect of very low density lipoproteins on lipid transfer in incubated serum. J. Lipid Res. 6: 206-210.

PHILlIPS, G.B. and DODGE, J.T. (1967). Composition of phospholipids and of phospholipid fatty acids of human plasma. J. Lipid Res. 8: 676-681.

REED, C.F. (1968). Phospholipid exchange between plasma and erythrocytes in man and the dog. J. Clin. Invest. 47: 749-760.

SKIPSKI, V.P., PETERSON, R.F. and BARCLAY, M. (1964). Quantitative analysis of phospholipids by thin-layer chromatography. Biochem. J. 90: 374-378.

SNIDERMAN, A.D., TENG, B., VEZINA, C. and MARCEL, Y.L. (1978). Cholesterol ester exchange between human plasma high density lipoproteins and low density lipoproteins mediated by a plasma protein factor. Atherosclerosis 31: 327-333.

STOKKE, K.T. and NORUM, K.R. (1971). Determination of lecithin:cholesterol acyltransferase in human blood plasma. Scand. J. Clin. Lab. Invest. 27: 21-27.

SUBBAIAH, P.V. and BAGDADE, J.D. (1978). Demonstration of enzymatic conversion of lysolecithin to lecithin in normal human plasma. Life Sci. 22: 1971-1978.

SUBBAIAH, P.V. and BAGDADE, J.D. (1979). Association of lysolecithin acyltransferase with the high density lipoprotein and its activation by the low density lipoproteins in normal human plasma. Biochim, Biophys. Acta 573: 212-217.

TALL, A.R. and SMALL, D.M. (1978). Plasma high density lipoproteins. New Eng. J. Med. 299: 1232-1236. 
WALKER, J.L., CHAMBERLAIN, S. and ROBINSON. N. (1980). Lipids and lipoproteins in Friedreich's Ataxia. J. Neurol. Neurosurg. Psych. 43: 111-117.
YAO, J.K. and DYCK, P.J. (1978). Lipid abnormalities in hereditary neuropathy, Part 2: Serum phospholipids. J. Neurol. Sci. 36: 225-236.
YAO, J.K., ELLEFSON, R.D. and DYCK, P.J. (1976). Lipid abnormalities in hereditary neuropathy, Part 1: Serum non-polar lipids, J. Neurol. Sci. 29: 161-175. 